\title{
Nutritional, Phytochemicals and Antioxidant Properties of Some Popular Pulse Varieties of Bangladesh
}

\author{
Tanvir Ahmmed1, Asma Rahman², Umme Salma1, Zakia Akter3, Md. Mesbah Uddin Ansary1, \\ Md. Ibrahim Khalil', Nurul Karim1, Latiful Bari2*
}

\footnotetext{
${ }^{1}$ Laboratory of Preventive and Integrative Biomedicine (PIB), Department of Biochemistry and Molecular Biology, Jahangirnagar University, Savar, Dhaka, Bangladesh

${ }^{2}$ Food Nutrition \& Agricultural Research Unit, Center for Advanced Research in Sciences (CARS), University of Dhaka, Dhaka, Bangladesh

${ }^{3}$ Department of Biochemistry and Molecular Biology, Gono Bishwabidyalay, Savar, Dhaka, Bangladesh

Email: *latiful@du.ac.bd, sadiqur_rahman2002@yahoo.com, ansarymu.ju@juniv.edu.bd, drmikhalil@gmail.com
}

How to cite this paper: Ahmmed, T., Rahman, A., Salma, U., Akter, Z., Ansary, M.M.U., Khalil, M.I., Karim, N. and Bari, L. (2020) Nutritional, Phytochemicals and Antioxidant Properties of Some Popular Pulse Varieties of Bangladesh. Journal of Agricultural Chemistry and Environment, 9, 343-368

https://doi.org/10.4236/jacen.2020.94025

Received: September 23, 2020

Accepted: November 27, 2020

Published: November 30, 2020

Copyright $\odot 2020$ by author(s) and Scientific Research Publishing Inc. This work is licensed under the Creative Commons Attribution International License (CC BY 4.0).

http://creativecommons.org/licenses/by/4.0/

\begin{abstract}
In this study, we estimate the proximate compositions, phytochemicals (polyphenol, flavonoids, flavonol, tannin, protein, carbohydrate, reducing sugar, and $\beta$ carotene), antioxidant activities, vitamins, minerals, and heavy metals of the four pulses (mung, anchor, chickpea, lentils) and compare among them to find out more nutritious pulse samples. Mung was found to contain the highest amount of polyphenol (98.02 $\pm 1.74 \mathrm{mg}$ GAE$/ 100 \mathrm{~g})$ and tannin (447.98 $\pm 9.96 \mathrm{mg}$ TE/100 g) and anchor $(771.35 \pm 3.76 \mathrm{mg} \mathrm{CE} / 100 \mathrm{~g})$ was rich in flavonoids as compared to other two pulse samples. Mung was also rich in ash, carbohydrate, vitamin $B_{1}$, copper and anchor was rich in crude fiber, protein, reducing sugar, and vitamin $B_{2}$ content. The highest amount of phytochemicals contained in mung and anchor corresponded to its highest antioxidant activity in analyzed antioxidant assays respectively. Other two pulses included in this study were found to contain good source of vitamins, minerals and other nutrients.
\end{abstract}

\section{Keywords}

Pulses, Phytochemicals, Antioxidant Activity, Nutrients, Bangladesh

\section{Introduction}

Pulses are members of family leguminosae which belong to a large number of plant species grown all over the world as a dried seed [1]. They have been be- 
ing part of human diet since 10,000 years ago in respect to historical records of pulse consumption [2]. Pulses, one of the edible seeds, are the good source of protein, carbohydrates, vitamins, minerals such as iron, zinc, magnesium, calcium, potassium, phosphorous, and fiber as well as rich in trivial amount of fat in human diet [3]. Pulses alone can provide approximately 300 to $540 \mathrm{Kcal} / 100 \mathrm{~g}$ energy which comes from carbohydrate, protein, and fat content [4]. Additionally, they are rich in various bioactive phytochemicals such as polyphenols, tannins, flavonoids, flavonols, etc. that confer antioxidant activities against oxidative stresses produced in case of redox reactions in response to different types of free radicals (superoxide radicals $\left[\mathrm{O}_{2}^{-}\right]$, hydroxyl radicals $[\bullet \mathrm{OH}]$, singlet oxygen $\left[{ }_{1} \mathrm{O}_{2}\right]$, and hydrogen peroxide $\left.\left[\mathrm{H}_{2} \mathrm{O}_{2}\right]\right)$ [5]. The antioxidant properties of pulses also show a wide range of health benefits such as anti-allergenic, anti-inflammatory, anti-artherogenic, anti-microbial, cardioprotective, and vasodilatory effects [6]. According to epidemiological and intervention studies, pulses have received much attention as alternative therapeutic agents because of having bioactive ingredients providing protection against various oxidative stresses induced diseases such as type II diabetes mellitus, coronary heart diseases and obesity [7]. Being good source of dietary fiber, pulse can regulate cholesterol level (Lower LDL and Higher HDL) and promote healthy bowel function in the individuals who take it on a regular daily basis. Pulses also have low glycemic index that can decrease glucose and insulin level [8]. Although pulse is widely grown in many countries such as India, Pakistan, Myanmar, Thailand, Philippines, China, and Indonesia, the production rate of pulse in Bangladesh is not sufficient and decreasing to meet the demand of the country [9]. Only about 7.3 lakh hectare of land ( $9 \%$ of the net cropped area) of the country is devoted to pulse cultivation as a result, pulse is imported in large amounts from India. According to the report of World Health Organization (WHO), the daily recommended consumption rate of pulse is $45 \mathrm{gram} / \mathrm{capita} /$ day whereas the daily pulse consumption rate in Bangladesh is only $17 \mathrm{gram} / \mathrm{capita} /$ day [10]. Following recommended consumption rate and taking enough pulses in diet as they are a cheaper source of animal proteins, it is possible to eradicate the protein-calorie malnutrition problems and improve the health conditions of people in Bangladesh [11]. In Bangladesh, pulses are known only as the protein source rather than its other nutritional values. To date, numerous studies regarding compositions of pulses have been extensively done in many countries including nutritional and phytochemical contents, but no single study has been conducted in Bangladesh to report the proximate compositions, nutritional amounts, and bioactive components of pulses commonly consumed in daily diet. Therefore, this study aims to investigate the proximate compositions, phytochemical properties, antioxidant activities, and nutritional value of the four pulse samples which were Lentil, Mung bean, Chickpea and Anchor available in Bangladesh (Figure 1) and find out which one is more beneficial in these aspects to meet the daily diet requirements of Bangladeshi people. 


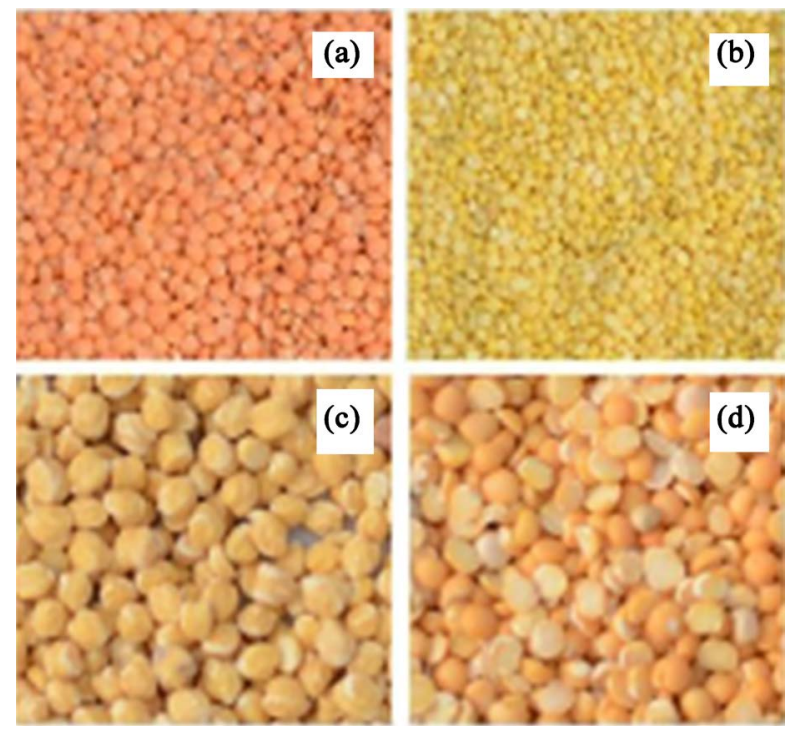

Figure 1. Pulse samples. (a) Lentil, (b) Mung Bean, (c) Chickpea and (d) Anchor.

\section{Materials}

\section{Chemicals and Reagents}

Standards gallic acid, catechin, quercetin, tannic acid, green vitriol $\left(\mathrm{FeSO}_{4}\right.$, $7 \mathrm{H}_{2} \mathrm{O}$ ), ascorbic acid, 1,1-diphenyl-2-picrylhydrazyl radical (DPPH), 2,4,6-tris (2-pyridyl)-1,3,5-triazine (TPTZ) were purchased from Sigma-Aldrich (St. Louis, $\mathrm{MO})$. Aluminium chloride $\left(\mathrm{AlCl}_{3}\right)$, sodium nitrite $\left(\mathrm{NaNO}_{2}\right)$, hydrogen peroxide $\left(\mathrm{H}_{2} \mathrm{O}_{2}\right)$, sodium hydroxide $(\mathrm{NaOH})$, sodium acetate $\left(\mathrm{C}_{2} \mathrm{H}_{3} \mathrm{NaO}_{2}\right)$, ammonium molybdate $\left(\mathrm{NH}_{4}\right)_{2} \mathrm{MoO}_{4}$, Tri Chloro Acetic acid (TCA), sodium carbonate $\left(\mathrm{Na}_{2} \mathrm{CO}_{3}\right)$ were purchased from Merck Co. (Darmstadt, Germany). Vitamin $\mathrm{B}_{1}$ and $\mathrm{B}_{2}$ standards (Thiamine $\mathrm{HCl}$ and Riboflavin) were purchased from DUCHEFA (Haarlem the Netherlands). All of the chemicals and reagents used in this study were of analytical grade.

\section{Methods}

\subsection{Sample Collection and Processing}

Four varieties of pulse samples (Table 1) were purchased from the local market (also known as kacha Bazar) in Savar, Dhaka, Bangladesh in May, 2018. All the samples were washed to remove sands and dirt from them. All the samples were further dried in sunlight. The samples were powdered using a grinder machine and stored in an air tight container to be used for extraction process.

\subsection{Extract Preparation}

Briefly, the powdered pulse of four samples (500 g) was dissolved with pure ethanol (100\%) for 5 days. During this time, this mixture was shaken at regular interval for mixing the sample with solvent properly. Then the extract was filtered through cotton cloth and then through Whatman no. 1 filter paper which was fitted with a suction (Rocker 300) apparatus and the filtrate was collected. 
Table 1. Popular pulse varieties consumed in Bangladesh.

\begin{tabular}{cc}
\hline Common Name & Scientific Name \\
\hline Lentil & Lens culinaris \\
Mung bean & Vigna radiata L. \\
Chickpea & Cicer arietinum L. \\
Anchor & Pisum Sativum var. arvense L. Poiret \\
\hline
\end{tabular}

The collected filtrate was kept in a rotary evaporator to be dried (Buchi, Tokyo, Japan) under reduced pressure $(100 \mathrm{psi})$ and controlled temperature $\left(100^{\circ} \mathrm{C}\right)$. For the complete evaporation of residual ethanol, semisolid extract was incubated overnight in an incubator at $45^{\circ} \mathrm{C}$. Finally, the dried extract (lentil $11.35 \mathrm{~g}$, mung bean $7.18 \mathrm{~g}$, chick pea $16.25 \mathrm{~g}$, and anchor $9.08 \mathrm{~g}$ ) was preserved at $-20^{\circ}$ for subsequent analysis.

\subsection{Statistical Analysis}

All analyses were performed in triplicate and the data were reported as the mean \pm standard deviation. They were subjected to two tailed $\mathrm{t}$-test $(\mathrm{p}<0.05)$ to assess the variation of values given by each samples as statistical significant value. Data were analyzed using Microsoft Excel 2013 (Redmond, Washington, USA).

\subsection{Nutritional Composition of Pulse Varieties}

Nutritional Composition of pulse samples was analyzed using following methods $\mathrm{pH}$ by $\mathrm{pHPW}$ ( $\mathrm{pH}$ for dry powder) method, moisture by the weighed moisture box (A \& D Company Ltd. N 92; P1011656, Japan), ash by AOAC Official Method 942.05 with slight modification, lipid by soxhlet extraction method, and crude fiber by AOAC, $962.09,16^{\text {th }}$ edition method with some modifications respectively.

\subsubsection{Carbohydrate Content}

Determination of total carbohydrate was carried out by phenol-sulfuric acid method according to (Agrawal, 2015) with some modifications. Dextrose (7.813 - $125 \mu \mathrm{g} / \mathrm{ml}$ ) was used as a standard and the results were expressed as grams of DEs equivalents per $100 \mathrm{~g}$ of sample extract.

\section{Principle of Phenol-sulfuric acid method}

In hot acidic medium, carbohydrate is dehydrated to hydroxyl-methyl furfural. This forms a green colored product with phenol and has absorption maximum at $490 \mathrm{~nm}$.

\section{Some Modifications}

\section{Original method}

Different concentration of sample and $1 \mathrm{ml}$ of standard were added to each test tube. Then added $1 \mathrm{ml}$ of $5 \%$ phenol solution to each tube. After that added $5 \mathrm{ml}$ of concentrated sulfuric acid to these, mixed well and waited for $10 \mathrm{mi}-$ nutes. Then boiling in a water bath for 15 minutes at $25^{\circ} \mathrm{C}-30^{\circ} \mathrm{C}$. Finally meas- 
ured absorbance at $490 \mathrm{~nm}$ against a blank by using spectrophotometer.

\section{Modifications}

Different concentration of $0.2 \mathrm{ml}$ sample and standard were added to each test tube. Then added $0.2 \mathrm{ml}$ of $5 \%$ phenol solution to each tube. After that added 1 $\mathrm{ml}$ of concentrated sulfuric acid to these, mixed well and waited for 10 minutes. Then boiling in a water bath for 20 minutes at $25^{\circ} \mathrm{C}-30^{\circ} \mathrm{C}$. Finally measured absorbance at $490 \mathrm{~nm}$ against a blank by using spectrophotometer.

\subsubsection{Protein Content}

Total protein content in pulse extracts was estimated by Lowry's method of protein estimation. Bovine serum albumin (BSA) $(0.2-1 \mathrm{mg} / \mathrm{ml})$ was used as a standard and the results were expressed as milligram of BSA equivalents per $100 \mathrm{~g}$.

\subsection{Phytochemical Analysis}

\subsubsection{Estimation of Total Polyphenol Content}

The total polyphenol content of each sample extract was estimated by spectrophotometric determination according to Modified Folin-Ciocalteu method. The total polyphenol content present was determined as gallic acid equivalents (GAEs) $(20-100 \mu \mathrm{g} / \mathrm{mL})$ and expressed as milligram of GAEs per $100 \mathrm{~g}$ of sample extract.

\subsubsection{Estimation of Total Flavonoid Content}

The total flavonoid content was estimated by Aluminium chloride colorimetric assay. The total flavonoid content present was determined as Catechin equivalents (CEs) and was expressed as milligram of CEs per $100 \mathrm{~g}$ of sample extract.

\subsubsection{Estimation of Total Flavonol Content}

The total flavonol content of the sample was determined according to the method previously used [12]. The concentration of total polyphenol content was determined as Quercetin equivalents (QEs) $(62.5-1000 \mu \mathrm{g} / \mathrm{mL})$, and the result was expressed as milligram of QEs per $100 \mathrm{~g}$ of sample extract.

\subsubsection{Estimation of Tannin Content}

Tannic acid in sample extracts was estimated following Folin-Ciocalteu's method with tannic acid as standard. The results were expressed as milligram of tannic acid equivalents (TEs) per $100 \mathrm{~g}$ of sample extract.

\subsubsection{Reducing Sugar}

The estimation of reducing sugar content was carried out according to Nelson-Somogyi method with slight modification. Dextrose was used as a standard to prepare a standard curve $(1.56-50 \mu \mathrm{g} / \mathrm{mL})$, and reducing sugar content was expressed as grams of DEs per $100 \mathrm{~g}$.

\subsubsection{Estimation of $\beta$ Carotene Content}

$\beta$ Carotene was determined According to the method of Nagata and Yamashita described by L. Barros et al. 2007. Contents of $\beta$ carotene were calculated using 
the following equation:

$$
\beta \text { Carotene }(\mathrm{mg} / 100 \mathrm{ml})=0.216 A_{663}-0.304 A_{505}+0.452 A_{453} ;
$$

The assays were carried out in duplicate; the results were calculated as mean \pm standard deviations (SD) and expressed as $\mathrm{mg}$ of carotenoid/100 $\mathrm{g}$ of extract.

\subsection{Antioxidant Activity}

\subsubsection{Ferric Reducing Antioxidant Power (FRAP) Assay}

Modified Benzie et al. 2017 method was followed in Ferric Reducing Antioxidant Power (FRAP) assay. Antioxidant activity of green vitriol was used as a reference standard. All the samples indicated a concentration dependent total antioxidant capacity.

\subsubsection{Total Reducing Power Assay}

Total reducing power assay was determined by Oyaizu, M. et al. 1986. Total reducing power of ascorbic acid was used as standard. All the samples indicated a concentration dependent total reducing power.

\subsubsection{Phosphomolybdate Method}

The total antioxidant activity (TAC) of sample was determined by phosphomolybdate method according to Shabbir et al. 2013 with slight modifications. Antioxidant activity of catechin $(7.81-500 \mu \mathrm{g} / \mathrm{ml})$ was used as a reference standard. All the samples indicated a concentration dependent total antioxidant capacity.

\subsubsection{Free Radical-Scavenging Ability by the Use of DPPH Radical}

The radical scavenging activity of pulse extract was carried out using the DPPH (1,1 Diphenyl 2-Picryl Hydrazyl) assay according to the following methods with some modifications [13]. The percentage of inhibition of samples was calculated from obtained absorbance by following equation:

$$
\text { DPPH inhibition }=[(\text { Abs control }- \text { Abs sample }) / \text { Abs control } \times 100] \%
$$

where Abs control = absorbance of DPPH radical in the absence of sample, Abs sample $=$ absorbance of DPPH radical in the presence of either the extract or the standard.

The value was determined by plotting the absorbance data (\% of DPPH inhibition) against the log of measured concentrations using the slope of the nonlinear regression. The DPPH-scavenging activity was expressed as the amount of sample necessary to decrease the absorbance of DPPH by $50 \%\left(\mathrm{IC}_{50}\right)$. A smaller $\mathrm{IC}_{50}$ value corresponds to a higher antioxidant activity.

\subsubsection{Hydrogen Peroxide $\left(\mathrm{H}_{2} \mathrm{O}_{2}\right)$ Scavenging Capacity}

Hydrogen peroxide $\left(\mathrm{H}_{2} \mathrm{O}_{2}\right)$ scavenging capacity was determined using the method with some modifications [14]. The percentage of hydrogen peroxide scavenging was calculated based on the following equation:

$$
\mathrm{H}_{2} \mathrm{O}_{2} \text { Scavenging }=\left[\left(A_{0}-A_{1}\right) / A_{0} \times 100\right] \%
$$


where $A_{0}$ was the absorbance of the control, and $A_{1}$ was the absorbance of the sample or standard.

$A$ curve was plotted between the percentages of hydrogen peroxide scavenging against concentration in $\mu \mathrm{g} / \mathrm{ml}$. The equation of this curve allowed to calculate the $\mathrm{IC}_{50}$ corresponding to the sample concentration required to reduce hydrogen peroxide scavenging absorbance by $50 \%$.

\subsection{Micronutrients Composition of Pulse Varieties}

\subsubsection{Vitamin A Content by Retinol Equivalent (RE)}

Vitamin A content of pulse varieties was estimated using the method where established the following relationships to determine the Vitamin A contents in diets considering different food sources and factors [15]:

$1 \mu \mathrm{g}$ retinol $=1 \mathrm{RE}$ method used. Variation in ecological growth conditions.

$1 \mu \mathrm{g} \beta$-carotene $=0.167 \mu \mathrm{g} \mathrm{RE}$ like variety and environmental aspects may also be.

$1 \mu \mathrm{g}$ other pro-vitamin A carotenoids $=0.084 \mu \mathrm{g} \mathrm{RE}$ contributing factors.

\subsubsection{Estimation of Vitamin-B Complex $\left(B_{1} \& B_{2}\right)$ by HPLC}

Estimation of Vitamin $B$ complex $\left(B_{1}\right.$ and $\left.B_{2}\right)$ was carried out according to methods previously used with some modifications [16].

\section{Instrumentation}

High Performance Liquid Chromatographic system (Shimadzu-UFLC Prominence) which was equipped with an auto sampler (Model-SIL 20AC HT), and UV-Visible detector (Model-SPD 20A) and LC-solutions software was used for the analysis of sample.

\section{Extraction Solution}

Solution for the extraction was prepared taking $50 \mathrm{ml}$ of acetonitrile with 10 $\mathrm{ml}$ of glacial acetic acid and finally the volume was adjusted up to $1000 \mathrm{ml}$ with double distilled water.

\section{Sample Solution Preparation}

$10 \mathrm{gm}$ of each sample powder was mixed with $40 \mathrm{ml}$ of extraction solution into a conical flask and kept on shaking water bath at $70^{\circ} \mathrm{C}$ for 40 minutes. After cooling, the samples were filtered using $0.45 \mu \mathrm{m}$ size membrane filter followed by the cotton filter was used and finally the volume was made up to $50 \mathrm{ml}$ with extraction solution.

\section{Reference Solution Preparation}

For preparation of vitamin $\mathrm{B}_{1}$ (Thiamine $\mathrm{HCl}$ ) and vitamin $\mathrm{B}_{2}$ (riboflavin) reference solution, Thiamin hydrochloride $(10 \mathrm{mg}$ ) was dissolved in $100 \mathrm{ml}$ of extraction solution, and riboflavin (50 mg) was dissolved in $100 \mathrm{ml}$ of extraction solution and diluted to different concentrations as necessary.

\section{Buffer and Mobile phase preparation}

Hexane sulphonic acid sodium salt $(1.08 \mathrm{gm})$ and potassium dihydrogen phosphate $(1.36 \mathrm{gm})$ were dissolved in $995 \mathrm{ml}$ of double distilled HPLC water. Later, tri-ethylamine $(5 \mathrm{ml})$ was added and the $\mathrm{pH} 3.0$ was adjusted using or- 
thophosphoric acid. The prepared buffer was sonicated and filtered through membrane $(0.45 \mu \mathrm{m})$ filter. Mobile phase contained prepared buffer and HPLC grade methanol at 50:50 ratio.

Chromatographic Conditions

Column:

Flow rate of Mobile Phase:

UV Detection:

Temperature:

Injection Volume:
Analytical reversed Phase C-18 Column. $1 \mathrm{ml} / \mathrm{min}$. at $254 \mathrm{~nm}$. room temperature $\left(26^{\circ} \mathrm{C}\right)$. $20 \mu \mathrm{l}$ for both standard and sample solution.

Using mixed standards in mobile phase with five point calibrations, standard curve was made and analyzed independently. A standard curve was plotted between concentration and peak area. The data of peak area vs. used standard vitamin concentration were treated by linear least-square regression. The regression equation was obtained from standard curve and used to estimate vitamin $B$ complex $\left(\mathrm{B}_{1}\right.$ and $\left.\mathrm{B}_{2}\right)$ in different samples.

\subsubsection{Vitamin C Content}

Colorimetric estimation of Vitamin C (ascorbic acid) content of sample extracts was carried out according to the Omaye et al. 1979 with slight modification. The ascorbic acid concentration was determined as ascorbate equivalents (AEs) (0.78 - $25 \mu \mathrm{g} / \mathrm{mL}$ ) and ascorbic acid content was expressed as milligram of AEs per $100 \mathrm{~g}$ of sample extract.

\subsection{Minerals and Heavy Metals by AAS}

Minerals and Heavy metals were determined according to the method described by Anwar et al. 2008 with slight modifications by Atomic absorption spectroscopy (AAS). Briefly, $2 \mathrm{gm}$ of each sample powder was transferred into a $100 \mathrm{ml}$ glass beaker. In each beaker, $25 \mathrm{ml}$ of $65 \% \mathrm{HNO}_{3}$ was added, shaken, and kept aside for few minutes. Then the beakers were placed on the hot plate at $120^{\circ} \mathrm{C}$. After 1 hour of acid digestion, the beakers were put away from the hot plate, and $10 \mathrm{ml}$ of perchloric acid was added after cooling that turned solution into orange color. Then the digestion process was continued at the temperature between $100^{\circ} \mathrm{C}-135^{\circ} \mathrm{C}$. When the color of sample solution changed from orange to yellowish color, digestion process was completed. After cooling, $2 \mathrm{ml}$ of $\mathrm{HCl}$ and deionized water was added up to $60 \mathrm{ml}$ that made the color of the sample solution into light green color. Then, this solution was filtered through Whatman filter paper, and $40 \mathrm{ml}$ of deionized water was added to make the total volume of the sample up to $100 \mathrm{ml}$. Finally, the content of the flask was transferred into a plastic bottle for the assessment by an atomic absorption spectrophotometer (Shimadzu AA-7000). The absorbance of minerals (iron, zinc and copper) was measured at $248.3 \mathrm{~nm}, 213.8 \mathrm{~nm}$ and $327.4 \mathrm{~nm}$ respectively; and the absorbance of heavy metals (lead, cadmium, and chromium) was measured at $283.3 \mathrm{~nm}$, $228.8 \mathrm{~nm}$ and $327.9 \mathrm{~nm}$ respectively. 


\section{Results and Discussion}

\subsection{Nutritional Composition of Pulse Varieties}

\subsection{1. $\mathrm{pH}$}

$\mathrm{pH}$ value of a food exhibits the free hydrogen ions present in that food measure the free acidity. The range of $\mathrm{pH}$ is commonly considered to extend from zero to 14. Values less than 7 are considered as acidic $\mathrm{pH}$ and greater than 7 are basic or alkaline $\mathrm{pH}$. Most of the foods are naturally acidic in nature with acidic value less than 7.0. The $\mathrm{pH}$ value of the pulse found to be within range $6.28-6.59$ which is low acidic $\mathrm{pH}$ because it close to neutral $\mathrm{pH}(7.0)$. The $\mathrm{pH}$ of a food is one of several important factors that determine the survival and growth of microorganisms during processing, storage and distribution.

\subsubsection{Moisture Content}

Among the pulse samples lentil contained the highest moisture content followed by the anchor, mung and chickpea (Table 2). A study carried out by Habib Ullah et al. 2007 on the proximate composition of two varieties of mung reported result for moisture content was lower than our founding in the present study [17]. The possibility of highest moisture content in lentil because of the absorption of water by the outer coating and the filling of the gap between it and the cotyledon, leading to a marginal increase in volume. Moisture content of the pulse also depends on followings include the size of the seed and other agronomic factors, including maturity. In case of whole pulse a small quantity of moisture content absorbed by the seed coat through pores in the thin seed coat and in the gap between the seed coat and cotyledon [18].

\subsubsection{Ash Content}

Ash content of the pulse samples found to be highest in mung followed by lentil and anchor both contains equal amount of ash content. It had been found that the ash content in chickpea was low (Table 2). In studies carried out by Tosh et al. 2013 on the proximate composition of pulse varieties, reported result for ash content highest in mung followed by chickpea and lentil which was little bit lower than our founding in this aspect [19]. Total ash content indirectly indicate the mineral contents of the foodstuffs. Pulse crops absorb various minerals content from the soil where they cultivated. The Ash content of the pulse mainly depends on the soil conditions and weather of the cultivation land. Depending on these factors, the amount of ash is increased and decreased in the pulse sample.

\subsubsection{Total Lipid Content}

Tosh et al. 2013 reported lipid content of lentil and chickpea in their study was lower than present study for said pulses [19]. Although pulses are relatively poor in lipids, high variability could be observed from one pulse to another. Among the four samples, the total lipid content of the chickpea was higher than other pulses (Table 2). This is due to chickpea contains 4 to 10 fold higher sterol and 
phospholipid contents than other pulses [20]. Total lipid content of different pulse varies from each other and generally depends on origin, variety, location, climatic, seasonal, environmental conditions and soil type on which they grow [21].

\subsubsection{Crude Fiber}

Anchor contained the highest amount of crude fiber than other three pulses (Table 2). Although the amount of crude fiber should remain high in the pulse samples but in this study reported result was lower than other studies. Crude fiber of mung bean reported by Paul et al. 2011 which is much similar to present study but in case of other studies it was considerably low [22]. This could be as a result of origin, variety, location, climatic, seasonal, environmental conditions and soil type on which they grow. Crude fiber has many health beneficial effect including treating or preventing constipation, hemorrhoids, glucose modulation, coronary heart diseases and some type of cancer [23].

\subsubsection{Total Carbohydrate Content}

Carbohydrate content contributes a great deal to the energy supply [4]. Founding result showed that mung contained the highest amount of carbohydrate followed by the lentil, chickpea and anchor gradually (Table 2). The total carbohydrate content of the pulse samples was significantly $(\mathrm{p}<0.05)$ different from each other. In the present study, total carbohydrate content of the pulse samples was significantly lower than previous studies on the said pulses [22] [24]. The amount of total carbohydrate can be different among pulses because of the variability of sugar and fiber content among them.

\subsubsection{Protein Content}

The amount of protein in the food is measured in the basis of nitrogen content. Anchor contained the highest amount of protein and the lowest amount was present in chickpea (Table 2$)$. All the samples are significantly different $(\mathrm{p}<0.5)$ from each other. According to previous study protein content in the pulse varieties were comparatively higher than the founding in the present study [25]. The

Table 2. Nutritional composition of pulse varieties.

\begin{tabular}{ccccc}
\hline \multicolumn{5}{c}{ Nutritional composition } \\
\hline \multirow{3}{*}{ Parameters } & \multicolumn{4}{c}{ Amounts present in Varieties of Pulse } \\
\cline { 2 - 5 } & Lentil & Mung & Chickpea & Anchor \\
\hline Moisture Content (\%) & $11.81 \pm 0.01^{*}$ & $10.52 \pm 0.01^{*}$ & $10.04 \pm 0.01^{*}$ & $11.57 \pm 0.01^{*}$ \\
Ash Content (g/100 g) & $3.39 \pm 0.02^{*}$ & $4.43 \pm 0.02^{*}$ & $3.32 \pm 0.01^{*}$ & $3.39 \pm 0.02^{*}$ \\
Total Lipid (g/100 g) & $2.42 \pm 0.03^{*}$ & $2.09 \pm 0.02^{*}$ & $5.34 \pm 0.02^{*}$ & $2.31 \pm 0.04^{*}$ \\
Crude Fiber (g/100 g) & $0.65 \pm 0.02^{*}$ & $0.46 \pm 0.02^{*}$ & $0.72 \pm 0.03^{*}$ & $1.01 \pm 0.03^{*}$ \\
Carbohydrate (g/100 g DEs) & $5.4 \pm 0.16^{*}$ & $9.4 \pm 0.10^{*}$ & $3.8 \pm 0.09^{*}$ & $2.81 \pm 0.24^{*}$ \\
Protein (mg/100 g BSAEs) & $13.66 \pm 0.25^{*}$ & $14.79 \pm 0.05^{*}$ & $1.80 \pm 0.01^{*}$ & $428.37 \pm 0.00^{*}$ \\
\hline
\end{tabular}

Data are represented as the mean \pm standard deviation. ${ }^{*}$ All the pulse samples are significantly different $(\mathrm{p}$ $<0.05$ ) from each other. DEs, dextrose equivalents; BSAEs, bovine serum albumin equivalents. 
pulse seeds accumulate protein content mainly in the cotyledons which provides the free amino acids as well as ammonia and carbon skeletons during germination. Pulses are the good source of protein from plant origin which plays important role as building block of muscle mass and repair the damaged cells but in this study protein concentration was significantly low which could be influenced by environmental conditions and genetic factors [25].

\subsection{Phytochemical Analysis}

\subsubsection{Total Polyphenol Content}

Among the legumes the good source of polyphenols are dry legumes and also contribute in intake of polyphenol from other food source. These organic compounds have several biological effects including antioxidant, anti-aging, anti-inflammatory, apoptotic and cardiovascular protection [6]. It also has potentiality to bind with positively charged proteins, amino acids and minerals thus reduce the bioavailability of essential minerals and a reduction in their content may result in improved absorption of these nutrients [26]. Among the four varieties of pulse highest amount of polyphenol content found in mung followed by the lentil, anchor, and chickpea respectively (Table 3 ). All the pulse samples were significantly different $(\mathrm{p}<0.05)$ from each other. The amount of polyphenol in pulse samples were considerably lower than results founding in several studies [27]. Due to various factors such as plant genetics, soil composition and the growth conditions, the quality and quantity of polyphenols present in the plant food can greatly vary [26]. Though the amount of polyphenols in the present study was found to be lower than other studies but mung could be beneficial for human health if one take it in regular basis.

\subsubsection{Total Flavonoid Content}

The seed color of pulse grains depend on the presence of flavonoid compounds [27]. Flavonoids have antioxidant activities and wide range of physiological and biological activities. They can work against free radicals, inflammation, free radical mediated cellular signaling and platelet aggregation. They can prevent several disorders that can lead to cancer, provide protection against heart and brain diseases [6]. The total Flavonoid content of pulse samples were found to be highest in anchor and lowest in chickpea (Table 3) among the four pulse samples. However the amount of total flavonoid content was higher than the total polyphenol content of pulse samples. Amount of flavonoids in the pulse samples present in the following order anchor $>$ mung $>$ lentil $>$ chickpea respectively (Table 3). All the pulse samples were not significantly different $(\mathrm{p}>0.05)$ from each other. The level of total flavonoid content of pulse samples significantly higher than amounts found in several other studies [28]. Normally flavonoids and other phytochemicals remain in the seed coat of the pulse, various treatment like dehulling, soaking and cooking can reduce their amount in the pulse. Some flavonoids can give coat color of the seed have various health benefits as antioxidant [6]. Coat color of the seeds could be the cause of having the highest 
amount of flavonoids in the anchor and lowest in the chickpea.

\subsubsection{Flavonol Content}

Flavonols are one of the subgroups of large polyphenolic compound family flavonoids. The most widely distributed flavonoids in pulse is flavonols (3-hydroxyflavones) contributed in producing anti-inflammatory effects. The highest flavonol content was found in lentil followed by the mung, chickpea and anchor respectively (Table 3 ). All the pulse samples were significantly different $(\mathrm{p}<0.05)$ from each other. The amount of flavonol in pulse samples are significantly lower than total flavonoids content. As flavonols are the members of flavonoid family, they present in the seed coat and responsible for its color having antioxidant activity. Various processing methods dehulling or dehusking that remove the seed coat can affect the amount of flavonol content of sample. The health benefits of flavonols including have antioxidant properties and daily intake can reduce the risk of vascular diseases, can act as an anticancer effects and regulators of cellular signaling pathways [29]. Despite of its having lower quantity in pulse samples, pulse samples are highly rich in flavonoid content so it could be said that pulses have good antioxidant potentiality with various health benefits.

\subsubsection{Tannin Content}

Tannins mainly contained in the seed coat of pulses but physical removal of seed coat by dehulling or milling reduces $68 \%$ - $99 \%$ of tannins from the seeds. Overnight soaking of chickpea, mung bean in water and subsequent germination for 48 hours remove almost $50 \%$ of tannin content from the seeds [30]. All the pulse samples were significantly different $(\mathrm{p}<0.05)$ from each other. Among the pulse samples highest tannin was found in mung and lowest in the chickpea (Table 3 ). The level of tannin content in lentil and chickpea were significantly lower than the study carried out by Shweta et al. 2010 where founding tannin content for lentil was $305.4 \pm 62.26$ and for chickpea was $236.6 \pm 28.31 \mathrm{mg} / 100 \mathrm{~g}$ but in case of mung bean it was higher than the following study which was $395.9 \pm 9.82$ $\mathrm{mg} / 100 \mathrm{~g}$ [26]. In this study, it suggests that tannin content may contribute to the pulse antioxidant activities.

\subsubsection{Reducing Sugar}

The highest amount of reducing sugar found in anchor and the lowest amount in chickpea (Table 3). Samples were not significantly different $(p>0.05)$ from each other. Sugar contents are one kind of carbohydrates remain in the seed cotyledons. Processing of pulse seeds such as dehusking, soaking could reduce the amount of sugar content in the pulses [6]. Sugars present in the pulses playing important role in the digestive system by normalize the bowel function as well as increase the number of beneficial bacteria such as lactobacilli [24].

\subsection{6. $\beta$ Carotene}

$\beta$ carotene is a member of carotenoids family. It a yellowish-orange pigment 
normally found in foods from the plant sources especially in vegetables and fruits [31]. On the basis of $\beta$ Carotene amount found experimentally, the order of pulse samples was as follow: chickpea $>$ mung $>$ anchor $>$ lentil (Table 3 ). Results were expressed in the $\mathrm{mg} \mathrm{C} / 100 \mathrm{gm}$ of extract sample. All the samples were significantly different $(\mathrm{p}<0.5)$ from each other. In the present study, $\beta$-Carotene content of lentil and chickpea were found to be higher than study carried out by Jafar Qudah et al. 2014 on the carotenoids of the legumes by HPLC [32]. This may be due to the number of topographical factors including species variation, climate, soil type (red soil), rain fall, vegetation and geographic features. Also post-harvest conditions, such as time of picking to market (transportation), shelf time prior to purchase, may also influence the amounts of $\beta \mathrm{ca}$ rotene [33]. $\beta$ carotene plays various important role in human health include vitamin A formation, have antioxidant/pro-oxidant activity, immunological response, hormone regulation and fertility [34].

\subsection{Antioxidant Activities of Pulse Varieties}

\subsubsection{Ferric Reducing Antioxidant Power (FRAP) Assay}

Ferric Reducing Antioxidant Power assay measures the reducing potentiality of an antioxidant in a reaction in which it reacting with a ferric tripyridyltriazine [ $\left.\mathrm{Fe}^{3+}-\mathrm{TPTZ}\right]$ complex and in this reaction producing a coloured ferrous tripyridyltriazine $\left[\mathrm{Fe}^{2+}\right.$-TPTZ]. Generally reducing power is exhibited by the presence of compounds that show action by breaking the free radical chain by donating a hydrogen atom. In the sample FRAP assay treats as a reductant in a redox-linked colorimetric reaction [35]. The antioxidant activity by FRAP of pulse samples were graphically presented (Figure 2(a)). According to the figure total antioxidant activity by FRAP was found to be highest for anchor and lowest for chickpea. On the basis of the reducing activity, pulse samples showed the following order anchor $>$ lentil $>$ mung $>$ chickpea. All the samples indicated a concentration

Table 3. The phytochemical properties of pulses.

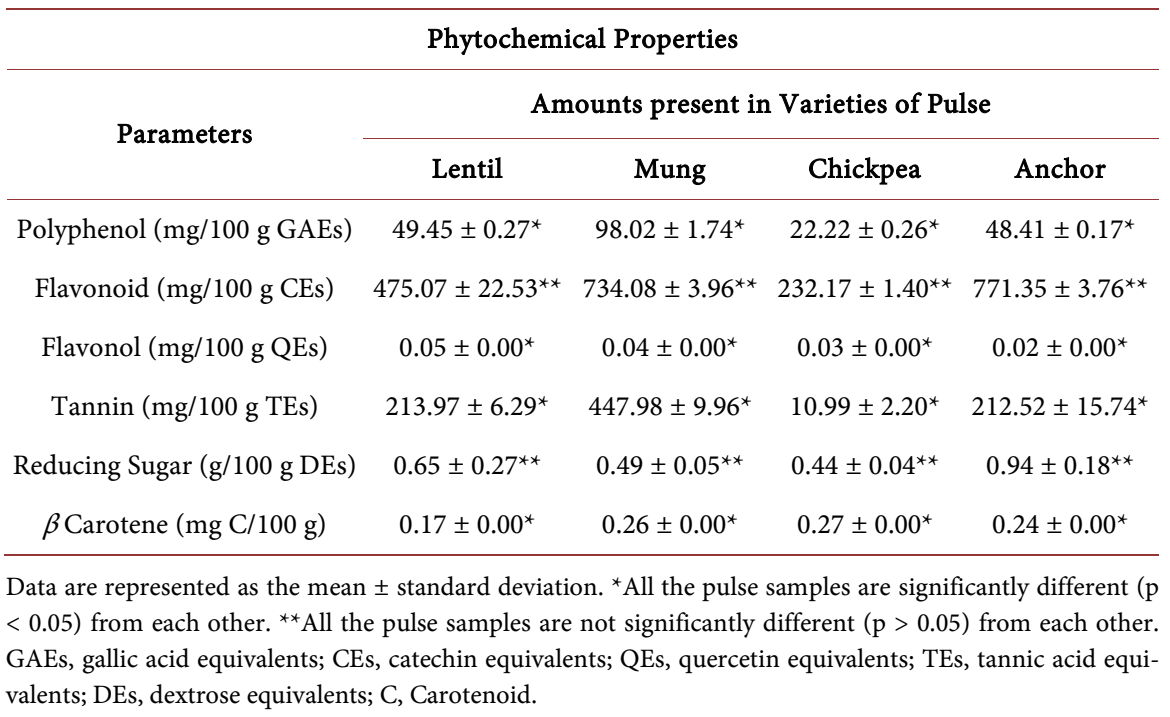


(a) Ferric Reducing Antioxidant

Power Assay

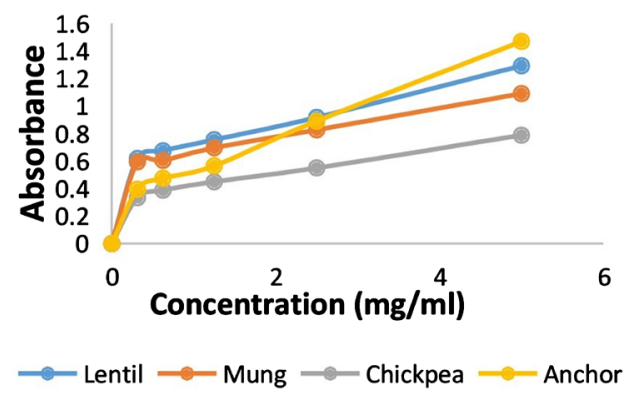

(b) Total Reducing Power

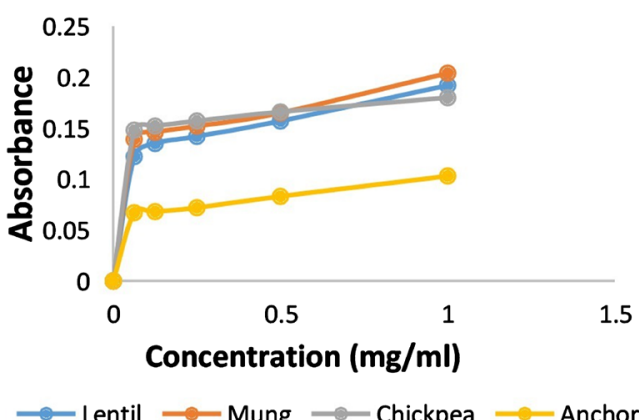

(c) Total Antioxidant Activity

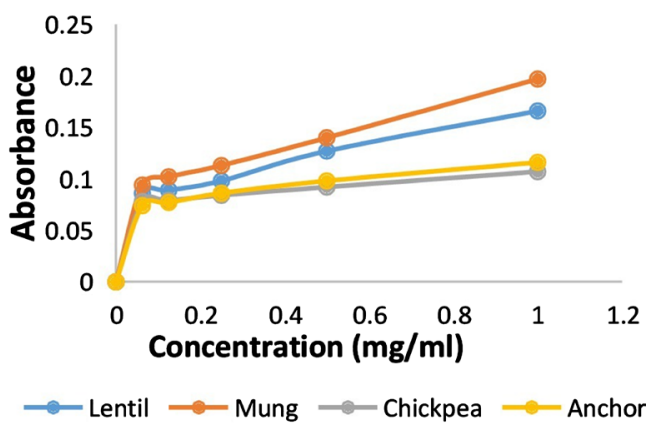

Figure 2. (a) Graphical presentation of total antioxidant activity by FRAP of different pulse samples, (b) Graphical presentation of total reducing power of different pulse samples, C) Graphical presentation of total antioxidant activity of different pulse samples.

dependent total antioxidant activity. Ferric reducing antioxidant power for pulses reported by Sreeramulu et al. 2009, observed the highest activity for mung and lowest in the lentil for the said pulses [36]. Increasing absorbance was shown for anchor with the increasing concentration due to the formation of $\mathrm{Fe}^{2+}-\mathrm{TPTZ}$ complex. They should be able to donate electrons to free radicals stable in the actual biological and food system. Earlier report of this study showed that flavonoid content was highest in the anchor and lowest in the chickpea this could be the cause of the highest reducing activity in anchor and lowest in chickpea. Antioxidant capacity of Green vitriol was used as a reference standard from which pulse samples potential activity were compared. 


\subsubsection{Total Reducing Power Assay}

Reducing power serve as a significant reflection of the antioxidant activity. Compounds that have reducing power serve as an electron donors and can reduce the oxidized intermediates of lipid peroxidation processes; in this way they can serve as a primary and secondary antioxidant. In this method, the presence of reducers can complete the conversion of the $\mathrm{Fe}^{3+}$ /ferricyanide complex to the ferrous form [37]. According to the (Figure 2(b)) highest reducing power was shown for mung. The reducing power activity for pulse sample showed following order mung $>$ lentil $>$ chickpea $>$ anchor. Reducing power was increased for the each sample with the increasing of the sample concentration. The highest reducing power is due to the presence of reducers which would have converted the $\mathrm{Fe}^{3+}$ /ferricyanide complex to the ferrous form and the lowest reducing power is due to the decreasing amount of reducers present in the sample. A study carried out by Bhumi et al. 2009 on the reducing power of the said pulse samples reported that the highest reducing power observed for lentil and chickpea; the lowest observed for mung and lentil respectively [28]. Phytochemical such as presence of polyphenols exert good antioxidant activity in the sample. Due to various factors such as plant genetics, soil composition and the growth conditions, the quality and quantity of polyphenols present in the plant food can greatly vary [26]. This might be the cause of variability for exerting reducing power of pulse samples. Total reducing power of Ascorbic acid was used as a reference standard from which pulse samples potential reducing power were compared.

\subsubsection{Total Antioxidant Activity by Phosphomolybdate Method}

The result of total antioxidant activity of pulse samples by Phosphomolybdate method was shown in Figure 2(c). It is based on the reduction of Mo (VI) to Mo (V) by the pulse samples and subsequent formation of green phosphate/Mo (V) complex at acid $\mathrm{pH}$. Total antioxidant activity of the phosphomolybdenum model evaluates both water-soluble and fat-soluble antioxidant capacity. The results indicated a concentration dependent total antioxidant capacity [38]. The total antioxidant activity of four pulses was found to be highest in the mung followed by the lentil, anchor and chickpea (Figure 2(c)). It means that different pulse sample would have contained as much quantity of antioxidant compounds as equivalents of catechin to effectively reduce the oxidant in the reaction matrix. Phytochemicals such as polyphenols, tannins were found to be highest in the mung and lowest in the chickpea earlier in this study (Table 3). These highest amounts of phytochemicals might be related with the highest antioxidant activity in mung among pulse samples. Antioxidant capacity of capacity of catechin was used as a reference standard from which pulse samples with potential antioxidant activity were compared.

\subsubsection{DPPH Free Radical Scavenging Activity}

DPPH is a nitrogen centered free radical donor usually used to estimate free radical scavenging activity of the plant extract or natural compounds. The com- 
pounds which have antioxidant activity donate an electron to the stable DPPH radical as a result the violet color of the DPPH radical was reduced to yellow colored Diphenylpicrylhydrazine radical which was measured colorimetrically. Substances which have capability to complete this reaction considered as radical scavenger [39]. The radical scavenging activity of the pulse samples was observed from the decrease in absorbance of the DPPH with a gradual increase in concentration of the sample at $517 \mathrm{~nm}$. This manifested in the rapid discoloration of the purple DPPH to discolor, suggesting that the radical scavenging activity of the pulse sample was due to its proton donating ability. The radical scavenging activity towards DPPH free radicals was expressed as percent inhibition (Figure 3(a)). The results showed that all the extracts displayed good scavenging activity in a dose dependent manner. From the half maximal inhibitory concentration $\left(\mathrm{IC}_{50}\right.$; the effective concentration at which the DPPH radicals were scavenged by $50 \%$ ), It was observed that, anchor showed the greatest scavenging activity with the $\mathrm{IC}_{50}-8.40$, followed by mung $\left(\mathrm{IC}_{50}-16.84\right)$, lentil $\left(\mathrm{IC}_{50}-17.69\right)$ and chickpea $\left(\mathrm{IC}_{50}-20.03\right) . \mathrm{IC}_{50}$ value is inversely proportional to the antioxidant activity of the sample. The results suggest that pulse samples are apparently good free radical scavengers (especially those of peroxy type) and probably have the ability to inhibit autoxidation of lipids and could thus be beneficial in the treatment of various diseases where lipid peroxidation is an important mechanism for pathogenesis [40]. Bhumi et al. 2009 \& Sreeramulu et al. 2009 carried out different studies on the freed radical scavenging activity of the pulses and legumes observed that the greatest scavenging activity was in lentil and mung; the lowest was in chickpea and lentil respectively for the said pulse samples. This could be the result of variability of phytochemicals which exert scavenging activity by donating electron. Present of the highest amount flavonoids content in the anchor (Table 3) might be the cause of its highest scavenging activity. DPPH scavenging activity of ascorbic acid was used as a reference standard $\left(\mathrm{IC}_{50} 2.48 \mu \mathrm{g} / \mathrm{ml}\right.$ ) from which pulse samples with potential radical scavenging activity were compared.

\subsubsection{Hydrogen Peroxide $\left(\mathrm{H}_{2} \mathrm{O}_{2}\right)$ Scavenging Activity}

Hydrogen peroxide is a weak oxidizing agent. Usually by causing oxidation of essential thiol (-SH) groups, it can directly inactive a few enzymes. If it can enter inside the cell, it have ability to cross cell membranes rapidly. Probably it reacts with $\mathrm{Fe}^{2+}$ and $\mathrm{Cu}^{2+}$ to form hydroxyl radical and this may be the origin of many of its toxic effects. It can produce in vivo by many oxidase enzymes such as superoxide dismutase [35]. The hydrogen peroxide scavenging activity of the pulse samples was graphically presented in Figure 3(b). The highest hydrogen peroxide scavenging activity was found for mung with $\mathrm{IC}_{50} 1.15 \mu \mathrm{g} / \mathrm{ml}$, followed by Anchor ( $\left.\mathrm{IC}_{50}-1.28\right)$, Chickpea $\left(\mathrm{IC}_{50}-2.17\right)$ and Lentil $\left(\mathrm{IC}_{50}-3.79\right)$. Bushra et al. 2015 carried out a study on the hydrogen peroxide scavenging activity of some mung and chickpea varieties reported that mung showed the highest scavenging activity than chickpea which is similar to our founding [7]. Pulse samples exerted a concentration dependent scavenging. Hydrogen peroxide scavenging 
(a) DPPH Radical Scavenging Activity

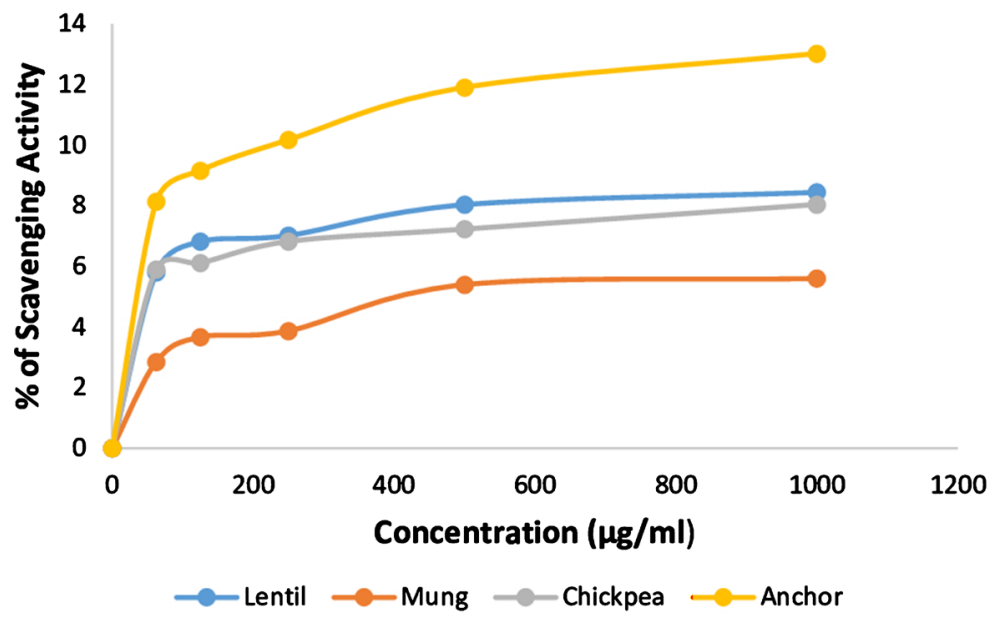

(b) Hydrogen Peroxide Scavenging Activity

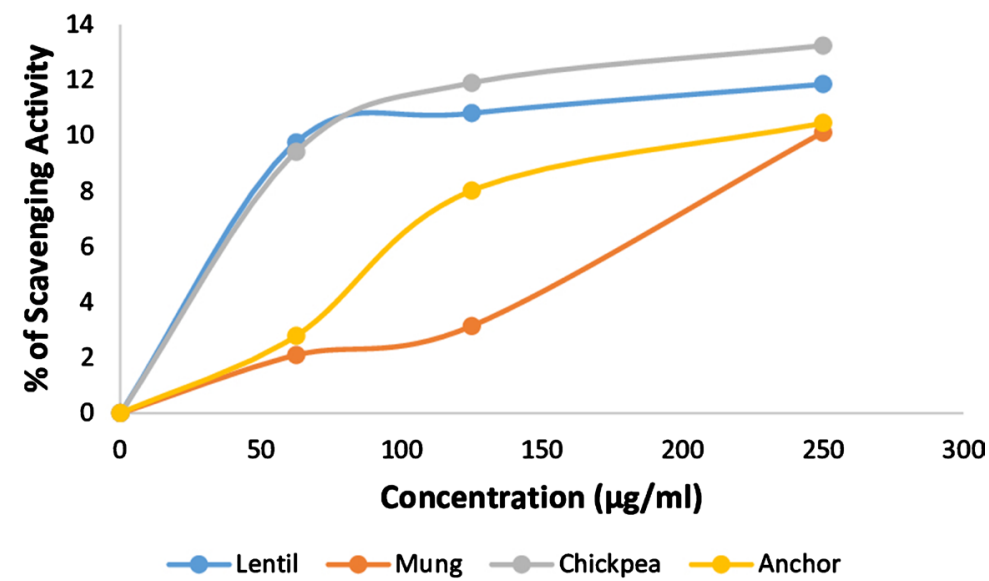

Figure 3. (a) Graphical presentation of DPPH scavenging activity of different pulse samples. (b) Graphical presentation of Hydrogen peroxide scavenging activity of different pulse samples.

activity of ascorbic acid was used as a reference standard $\left(\mathrm{IC}_{50} 0.852 \mu \mathrm{g} / \mathrm{ml}\right)$ from which pulse samples with potential hydrogen peroxide scavenging activity were compared. So, the order of scavenging activity among the pulses as follow: mung $>$ anchor $>$ chickpea $>$ lentil. The highest scavenging activity is due to presence of high amount phenolic compounds which act as free radical scavenger. These compounds have potential scavenging activity which may increase with concentrations.

\subsection{Micronutrients Composition of Pulse Varieties}

\subsubsection{Vitamin A Content}

The highest Vitamin A content was found in chickpea and lowest in the lentil (Table 6). Results were expressed in the International Unit (IU). All the samples were significantly different $(\mathrm{p}<0.05)$ from each other. Among the carotenoids, $\beta$ carotene content of the foods can converted into Vitamin A (Retinol) by chemi- 
cal transformation which is a pro-vitamin form of Vitamin A. In case of plant source, amount of vitamin $\mathrm{A}$ is directly or indirectly depended on the $\beta$ carotene content of that food content. Vitamin A content of the pulse samples were found to follow this order: chickpea $>$ mung $>$ anchor $>$ lentil (Table 6). There may be slight variation in the data when compared to other work done which may be due to difference in sources of vitamin A: experimental condition, extraction procedures, method used. Variation in ecological growth conditions like variety and environmental aspects may also be contributing factors [15].

\subsubsection{Estimation of Vitamin-B Complex $\left(\mathrm{B}_{1} \& \mathrm{~B}_{2}\right)$ by HPLC}

High Performance Liquid Chromatography (HPLC) is one of the most accurate and convenient analytical techniques. To analyze the Vitamin $B_{1} \& B_{2}$, a RP-HPLC method was used, mobile phase consisted of buffer and methanol in the ratio of 50:50 (v/v) over C-18 column $(250 \times 4.6 \mathrm{~mm}, 5 \mu \mathrm{m}$, Phenomenex, Inc.) at ambient temperature, flow rate was at $1 \mathrm{~mL} / \mathrm{min}$. The eluent was monitored at $254 \mathrm{~nm}$ by UV detector. The Retention Times (RT) of the vitamin $\mathrm{B}_{1}$ \& $\mathrm{B}_{2}$ were obtained as shown in Figure 4.

The method was found to be linear for the concentration range tabulated in Table 4. A good correlation coefficients $\left(R^{2}\right)$ were obtained as 0.9976 for thiamine $\mathrm{HCl}$ and 0.9999 for riboflavin respectively when peak areas were plotted against concentration levels (Figure 5). The slopes (m) of the calibration curve were found to be as 38,162 for thiamine $\mathrm{HCl}$ and 9932.30 for riboflavin respectively. The intercepts (c) of the calibration curve also were obtained to be as 72,924 and 9382.89 for thiamine $\mathrm{HCl}$ and riboflavin respectively.

For the estimation of Thiamine $\mathrm{HCl}$ and Riboflavin in different pulse samples the HPLC method was successfully performed. By comparing with standards shown in Figure 4 area of the Vitamin $B_{1}$ and $B_{2}$ in samples were identified (Table 5).

Each Vitamin was identified using the retention time, the absorbance spectrum profile and also by running the samples after the addition of pure standards. Quantification was performed by establishing curves for each vitamin determined, using the standards. Data are reported as means \pm standard deviations of triplicate independent analysis. Founding results are tabulated in Table 6. Mung contained highest amount of Thiamine $\mathrm{HCl}$ (Vitamin $\mathrm{B}_{1}$ ) followed by Chickpea and Anchor respectively (Table 6). In case of Vitamin B2, Anchor contained the highest amount Riboflavin followed by the Mung and Chickpea but in both cases amount of Vitamin $\mathrm{B}_{1} \& \mathrm{~B}_{2}$ in Lentil was below detection limit (Table 6). No significant interfering peaks were observed at the retention times of the standard vitamins. Effective separation and quantification of the two water-soluble vitamins was achieved in less than 10 mins. Vitamin $B_{1}$ and $B_{2}$ are fallen into water soluble category. Variability in the result has been found among the pulse samples. This can be greatly affected by the age or maturity and environmental conditions where they grow; these factors can changed the concentration of water soluble vitamin production in the pulse samples [41]. During 


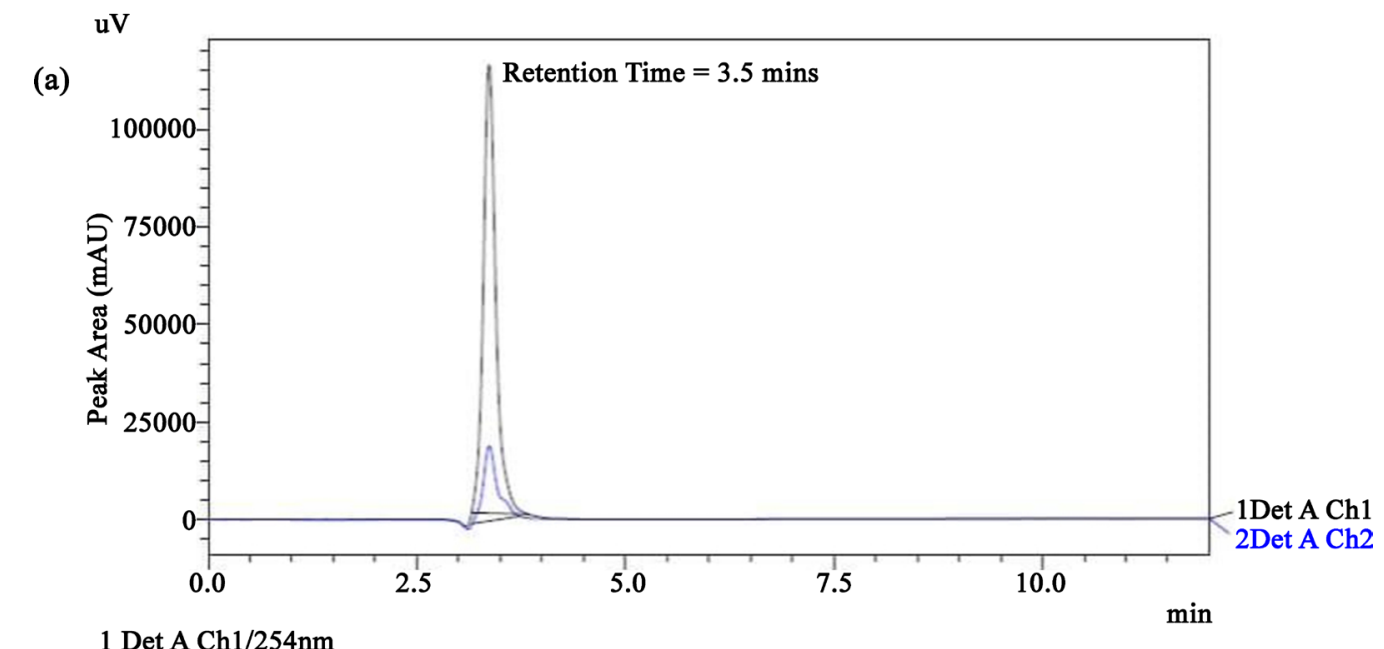

2 Det $A$ Ch2/290nm

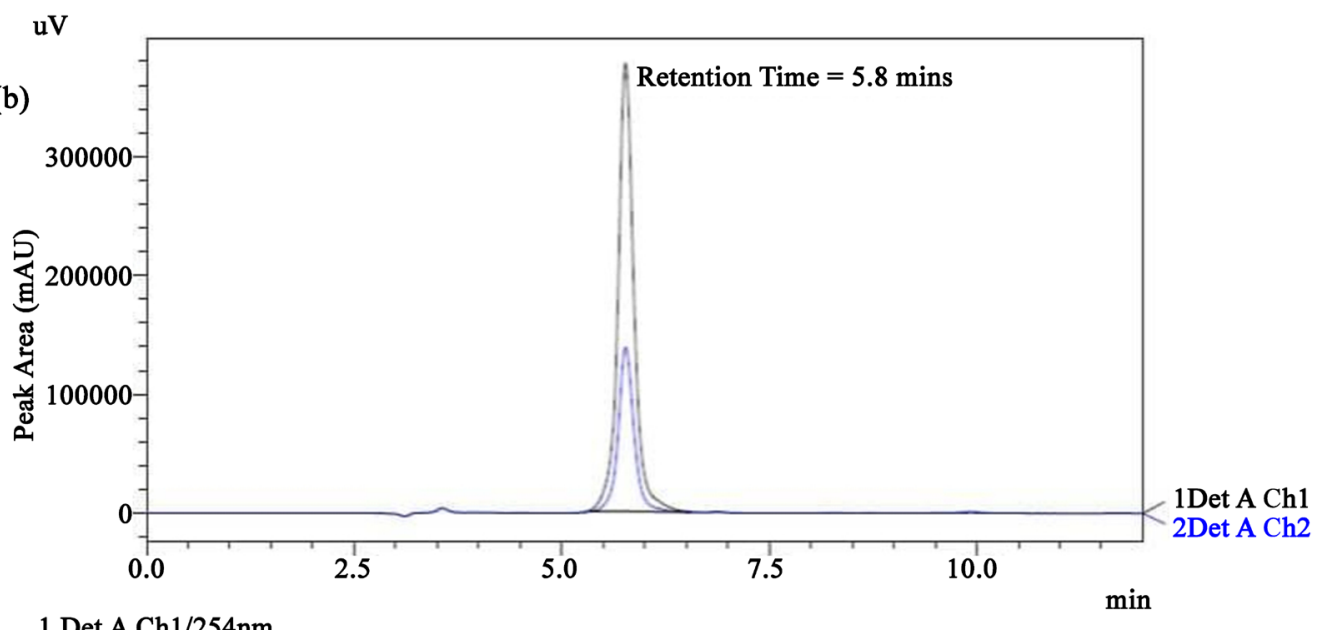

1/254nm

2 Det A Ch2/290nm

Figure 4. (a) Chromatogram of Vitamin $\mathrm{B}_{1}$ (Thiamine $\mathrm{HCl}$ ) standard. The retention time for Vitamin $\mathrm{B}_{1}$ was 3.5 minutes at $254 \mathrm{~nm}$, (b) Chromatogram of Vitamin $\mathrm{B}_{2}$ (Riboflavin) standard. The retention time for Vitamin $\mathrm{B}_{2}$ was 5.8 minutes at $254 \mathrm{~nm}$.

Table 4. The important parameters of the linearity curves for the standards.

\begin{tabular}{cccc}
\hline Vitamin & $\mathrm{y}=\mathrm{mx}+\mathrm{c}$ & $\left(\mathrm{R}^{2}\right)$ & Conc. range $(\mu \mathrm{g} / \mathrm{ml})$ \\
\hline $\mathrm{B}_{1}$ (Thiamine HCl) & $\mathrm{y}=38,162 \mathrm{x}+72,924$ & 0.9976 & $10-100$ \\
$\mathrm{~B}_{2}$ (Riboflavin) & $\mathrm{y}=9932.30 \mathrm{x}+9382.89$ & 0.9999 & $50-90$ \\
\hline
\end{tabular}

Table 5. Peak area of detection for Vitamin $B_{1}$ and $B_{2}$.

\begin{tabular}{ccc}
\hline Sample Name & Peak Area of Detection $\left(B_{1}\right)$ mAU & Peak Area of Detection $\left(B_{2}\right) \mathrm{mAU}$ \\
\hline Lentil & N/D & N/D \\
Mung & 324,928 & 20,154 \\
Chickpea & 121,833 & 16,642 \\
Anchor & 116,413 & 63,628 \\
\hline
\end{tabular}

mAU, milli absorbance unit; N/D, Not Detected. 

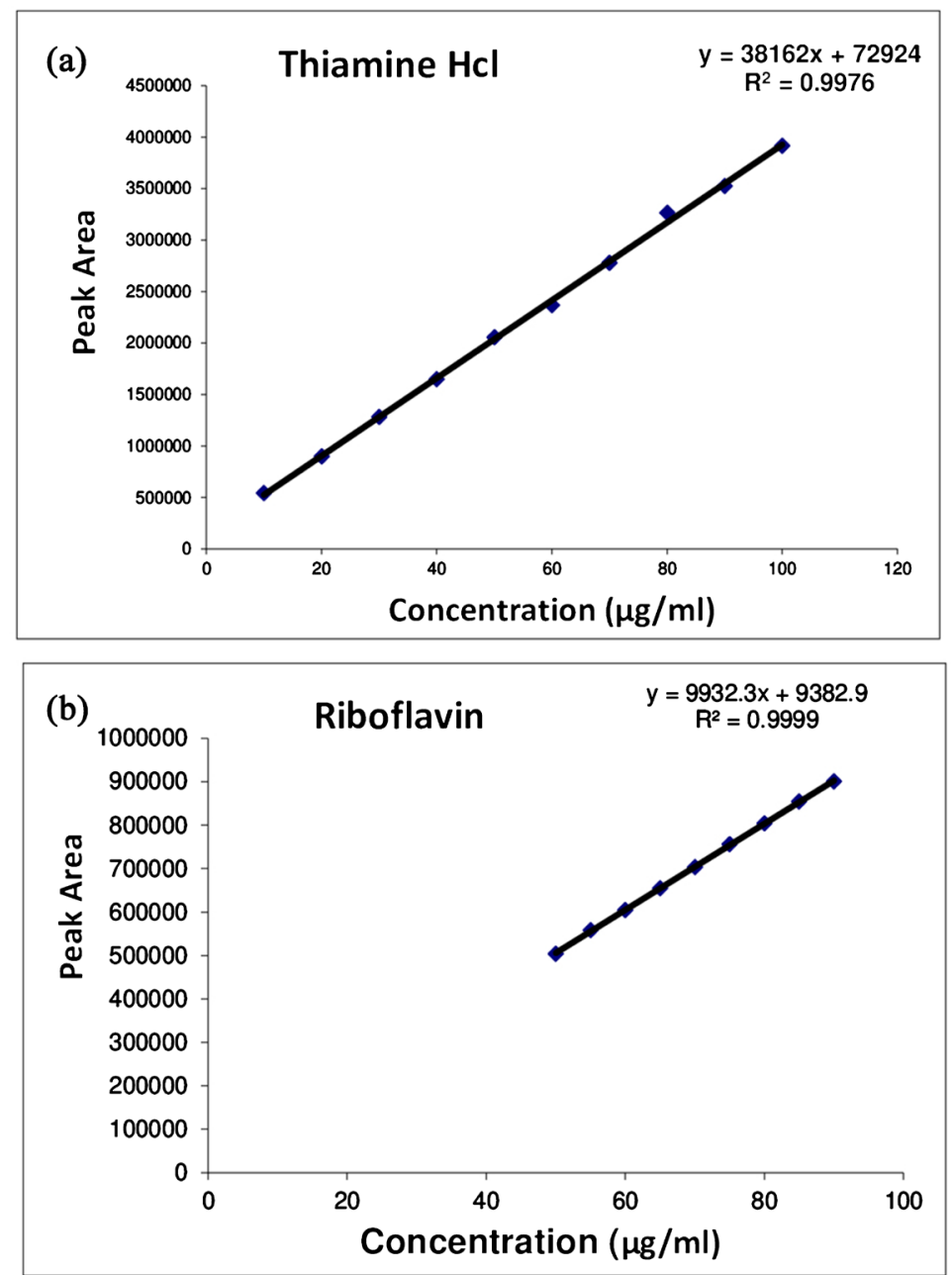

Figure 5. Calibration curve of Thiamine $\mathrm{HCl}\left(\right.$ Vitamin $\left.\mathrm{B}_{1}\right)$ and Riboflavin $\left(\right.$ Vitamin $\left.\mathrm{B}_{2}\right)$.

HPLC the retention time can also be affected by several factors that can bring variation in the result of sample include salt concentration and $\mathrm{pH}$ which have a considerable effect in the $\mathrm{C} 18$ reversed phase separation of vitamins. As a result the amount of vitamins per sample changed in study to study [42].

\subsubsection{Vitamin C Content}

According to the Vitamin C content the order of pulse samples were as follow lentil $>$ mung $>$ chickpea $>$ anchor (Table 6). All the samples were not significantly different $(\mathrm{p}>0.05)$ from each other. Investigation by Moriyama et al. 2008 on Vitamin C content on the legume seeds found $6.50 \pm 1.05 \mathrm{mg} / 100 \mathrm{Vi}$ tamin $\mathrm{C}$ content on mung bean, which was comparatively lower than our founding for mung [43]. Some factors that affects the level of Vitamin C such as variety, soil and growth condition, storage, refrigeration, removing of seed coat. As Vitamin C has the antioxidant activity some of the portion may be remain in the seed coat of pulse by removing them level of vitamin $c$ can decrease [44]. Pulses contain a considerably good amount of Vitamin C content showing good antioxidant activity that play preventive role against oxidative stresses in human 
body.

\subsubsection{Minerals}

In the present study, minerals $(\mathrm{Fe}, \mathrm{Zn} \& \mathrm{Cu})$ were estimated in the pulse samples by Atomic Absorption Spectroscopy (AAS). Iron ( $\mathrm{Fe}$ ) content of the pulse samples were found to be highest in lentil and lowest in mung. Amount of Iron content among the pulse samples showed the descending order of lentil $>$ anchor $>$ chickpea $>$ mung respectively (Table 6). All the samples were significantly different $(p<0.05)$ from each other. According to previous study, reported amount of iron for chickpea and mung was higher than the present study of said pulses [45]. The presence of iron in pulse samples may due to the occurrence of iron in the soil where the pulse crops were planted, which is affected due to variable capabilities of absorption and accumulation of iron by the pulse crops [46]. Trace element zinc is essential in very small concentrations for the survival of all life forms. Concentration of zinc in pulse samples from Table 6 lentil $0.07 \pm 0.00$, mung $0.04 \pm 0.00$, chickpea $0.08 \pm 0.00$ and anchor $0.06 \pm 0.00 \mathrm{ppm}$ respectively. According to present study the founding result for zinc content in pulse samples were much lower than some previous studies on the said pulse samples [45]. Zinc occurs naturally in soil but the concentrations are rising due to anthropogenic additions. They might arise from industrial activities such as mining, coal, waste combustion and steel processing. They can also originate from the use of

Table 6. Micronutrients and heavy metals content of pulse varieties.

\begin{tabular}{|c|c|c|c|c|}
\hline \multirow{2}{*}{ Parameter } & \multicolumn{4}{|c|}{ Vitamin Contents in Pulses } \\
\hline & Lentil & Mung & Chickpea & Anchor \\
\hline Vitamin A IU & $8.52 \pm 0.02^{*}$ & $13.03 \pm 0.03^{*}$ & $13.53 \pm 0.08^{\star}$ & $12.02 \pm 0.02^{*}$ \\
\hline Vitamin $B_{1}(\mathrm{mg} / 100 \mathrm{~g})$ & $\mathrm{N} / \mathrm{D}$ & $6.61 \pm 0.01^{*}$ & $1.29 \pm 0.01^{*}$ & $1.16 \pm 0.01^{*}$ \\
\hline Vitamin $B_{2}(\mathrm{mg} / 100 \mathrm{~g})$ & $\mathrm{N} / \mathrm{D}$ & $1.09 \pm 0.01^{*}$ & $0.72 \pm 0.02^{*}$ & $5.48 \pm 0.03^{*}$ \\
\hline Vitamin C (mg/100 g AEs) & $37.48 \pm 8.33^{* *}$ & $31.48 \pm 8.78^{* *}$ & $11.96 \pm 0.65^{\star *}$ & $9.84 \pm 3.47^{\star *}$ \\
\hline \multirow{2}{*}{ Parameter } & \multicolumn{4}{|c|}{ Amount (ppm) of Minerals in Pulses } \\
\hline & Lentil & Mung & Chickpea & Anchor \\
\hline Iron $(\mathrm{Fe})$ & $1.04 \pm 0.00^{*}$ & $0.73 \pm 0.00^{*}$ & $0.85 \pm 0.00^{*}$ & $0.98 \pm 0.00^{*}$ \\
\hline Zinc $(\mathrm{Zn})$ & $0.07 \pm 0.00^{*}$ & $0.04 \pm 0.00^{*}$ & $0.08 \pm 0.00^{*}$ & $0.06 \pm 0.00^{*}$ \\
\hline Copper $(\mathrm{Cu})$ & $0.09 \pm 0.00^{*}$ & $0.11 \pm 0.00^{*}$ & $0.07 \pm 0.00^{*}$ & $0.06 \pm 0.00^{*}$ \\
\hline \multirow{2}{*}{ Parameter } & \multicolumn{4}{|c|}{ Amount (ppm) of Heavy Metals in Pulses } \\
\hline & Lentil & Mung & Chickpea & Anchor \\
\hline Lead $(\mathrm{Pb})$ & $0.56 \pm 0.00^{* *}$ & $0.55 \pm 0.00^{* *}$ & $0.54 \pm 0.00^{* *}$ & $0.55 \pm 0.00^{\star *}$ \\
\hline Cadmium (Cd) & $\mathrm{N} / \mathrm{D}$ & $\mathrm{N} / \mathrm{D}$ & $\mathrm{N} / \mathrm{D}$ & $\mathrm{N} / \mathrm{D}$ \\
\hline Chromium (Cr) & $\mathrm{N} / \mathrm{D}$ & $\mathrm{N} / \mathrm{D}$ & $\mathrm{N} / \mathrm{D}$ & $\mathrm{N} / \mathrm{D}$ \\
\hline
\end{tabular}

Data are represented as the mean \pm standard deviation. ${ }^{\star}$ All the pulse samples are significantly different $(\mathrm{p}$ $<0.05)$ from each other. ${ }^{* *}$ All the pulse samples are not significantly different $(\mathrm{p}>0.05)$ from each other. AEs, ascorbate equivalents. IU: International Unit; N/D, Not Detected; ppm: parts per million. 
liquid manure, composed materials, fertilizers and pesticides in agriculture. These Zinc content of the soil are easily transferred from soil to edible portion of the plant and stored. Mainly zinc content of the soil is main factor for the variability of concentration in the food item [46]. The amount of zinc content in pulse samples from Table 6 were lentil $0.09 \pm 0.00$, mung $0.11 \pm 0.00$, chickpea $0.07 \pm 0.00$ and anchor $0.06 \pm 0.00 \mathrm{ppm}$ respectively. Highest amount of copper was found in mung followed by the lentil, chickpea and anchor. The amount of Copper for the pulse samples in the present study was lower than the previous study carried out by Salama et al. 2005. Trace metals such as copper is significant in nutrition for their essential nature or toxicity. Copper may enter the food materials from soil through mineralization by crops or environmental contamination with metal based pesticides. These can be vary with soil type, environmental factors, contamination ratio etc. The adult human body contains about 1.5 - 2 ppm of copper. Excessive intake has been reported to be toxic [47].

\subsection{Heavy Metal Analysis in Pulse Varieties}

Heavy metals which should remain a considerably lower amount in the food stuffs can be included in the food either by pollution or by absorbed from the soil. Excessive intake of these metals may cause serious health problem of human body. Islam et al. observed lead content in the lentil which was lower according to Table 6 for the said pulses [46]. In case of Cadmium the concentration of this metal was below detection limit in the sample by AAS as under the experimental condition it was not detected in this study. According to Salama et al. 2005 cadmium content was present on lentil and chickpea during their study. Lead can be deposited in the soil, water, plant from the air and reaching human via the food chain and causing renal tubular damage may also give rise to kidney damage. Amount of lead mainly vary on the degree of pollution with lead content. Cadmium is found as color pigment and in re-chargeable nickel-cadmium batteries. It is also present as a pollutant in phosphate fertilizers. Cadmium may present in the food stuff but vary in their concentration greatly [47]. The amount of chromium in the pulse samples were below detection limit as under the experimental condition in is not detected in the samples. A study carried out by Howe et al. 2005 on legumes and found chromium content. Though trivalent chromium is an essential nutrient for human which is involved in the glucose tolerance, the level of $\mathrm{Cr}$ in these samples calls for health concern. It can be transported by surface runoff to surface waters in its soluble or precipitated form. Plants absorb these metals from the soil and deposited it as a result concentration of $\mathrm{Cr}$ found in the crop derived food; this concentration is greatly variable [48].

\section{Conclusion}

We have studied the proximate compositions, phytochemical properties and antioxidant activities, vitamin, mineral and heavy metal content of four pulse sam- 
ples which are commonly consumed in Bangladesh. Pulses are one of the staple food in our daily diet. From this study, it has been found that pulses are the good source of phytochemicals such as polyphenols, flavonoids, flavonols and tannins; also have good antioxidant activity and other nutrients e.g. protein, carbohydrate, vitamins and minerals. Among the four pulses, mung rich in ash, carbohydrate, vitamin $\mathrm{B}_{1}$, copper $(\mathrm{Cu})$ content; in case of phenolic compounds it contains highest amount of polyphenol, tannin and anchor contains highest amount of flavonoids; these two varieties also have the greatest antioxidant capacity. Besides anchor is also found to be notable source of protein, reducing sugar, crude fiber, Vitamin $B_{2}$. So, it could be said that mung and anchor are more nutritious since both of them are rich in nutritional components compared to other two samples. These two pulses can prevent malnutrition in human body; may also exert protective role against oxidative stress related diseases such as type II diabetic mellitus, cardiovascular diseases, obesity etc. Considering the economical point of view anchor is cheaper than mung, it could be consumed in place of mung with same nutritional benefits. The results obtained and discussed in this study will provide good support to an individual aimed at selecting the best possible pulse among the four varieties considering his (or her) nutritional demand as well as economic conditions.

\section{Acknowledgements}

We gratefully acknowledge to Md. Khairul Islam of Wazed Miah Science Research Center, Jahangirnagar University, Savar, Dhaka-1342, Bangladesh, for his assistance with the AAS analysis.

\section{Funding}

This research did not receive any specific grant from funding agencies in the public, commercial, or not-for-profit sectors.

\section{Conflicts of Interest}

The authors declare no conflicts of interest regarding the publication of this paper.

\section{References}

[1] Rubatzky, V.E. and Yamaguchi, M. (1997) World Vegetables, Principles, Production and Nutritive Values. Chapman Hall (ITP), New York.

[2] Mikić, A. (2012) Origin of the Words Denoting Some of the Most Ancient Old World Pulse Crops and Their Diversity in Modern European Languages. PLoS ONE, 7, e44512. https://doi.org/10.1371/journal.pone.0044512

[3] Singh, A.K., Singh, S.S., Prakash, V., Kumar, S. and Dwivedi, S.K. (2015) Pulses Production in India: Present Status, Bottleneck and Way Forward. Journal of AgriSearch, 2, 75-83.

[4] Ofuya, Z.M. and Akhidue, V. (2005) The Role of Pulses in Human Nutrition: A Review. Journal of Applied Science \& Environment, 9, 99-104. 
https://doi.org/10.4314/jasem.v9i3.17361

[5] Hall, C., Hillen, C. and Robinson, J.G. (2017) Composition, Nutritional Value, and Health Benefits of Pulses. Cereal Chemistry, 94, 11-31.

https://doi.org/10.1094/CCHEM-03-16-0069-FI

[6] Gujral, H.S., Sharma, P., Gupta, N. and Wani, A.A. (2013) Antioxidant Properties of Legumes and Their Morphological Fractions as Affected by Cooking. Food Science and Biotechnology, 22, 187-194. https://doi.org/10.1007/s10068-013-0026-8

[7] Bushra, K., Bhanu, P.S.P., Kiran, B. and Pramod, S. (2015) A Comparative Study on the Antioxidant Properties of Some Edible Pulses. Indo American Journal of Pharmaceutical Sciences, 5, 3663-3666.

[8] Anderson, J.W. and Major, A.W. (2002) Pulses and Lipaemia, Short- and Long-Term Effect: Potential in the Prevention of Cardiovascular Disease. British Journal of Nutrition, 88, 263-271. https://doi.org/10.1079/BJN2002716

[9] Bhat, R., Sridhar, K.R. and Seena, S. (2008) Nutritional Quality Evaluation of Velvet Bean Seeds (Mucuna pruriens) Exposed to Gamma Irradiation. International Journal of Food Sciences and Nutrition, 59, 261-278.

https://doi.org/10.1080/09637480701456747

[10] Fakir, G., Rashid, M., Tonu, N., Haque, A. and Rahman, M. (2007) Production and Supply of Quality Healthy Seed of Pulse Crops in Bangladesh. In: Proceedings of the National Workshop on "Pulses for Nutrition, Security and Sustainable Agriculture", Bangladesh Agricultural Research Institute, Gazipur, 239.

[11] Nahar, Q., Faruque, M.O., Sultana, S.S.S. and Siddiquee, M.A. (2013) Desirable Dietary Pattern for Bangladesh. Bangladesh Institute of Research and Rehabilitation in Diabetes, Endocrine and Metabolic Disorders (BIRDEM). http://fpmu.gov.bd/agridrupal/sites/default/files/ToR15-Fial Report BIRDEM.pdf

[12] Kumaran, A. and Karunakaran, R.J. (2007) In Vitro Antioxidant Activities of Methanol Extracts of five Phyllanthus Species from India. LWT-Food Science and Technology, 40, 344-352. https://doi.org/10.1016/j.lwt.2005.09.011

[13] Hitoshi, A., Hideaki, T., Hirofumi, K. and Yoshinobu, K. (2004) Aging of Whiskey Increases 1,1-Diphenyl-2 picrylhydrazyl Radical Scavenging Activity. Journal of Agricultural and Food Chemistry, 52, 5240-5244. https://doi.org/10.1021/jf049817s

[14] Oktaya, M., Gulcin, I. and Kufrevioglub, O.I. (2003) Determination of in Vitro Antioxidant Activity of Fennel (Foeniculum vulgare) Seed Extracts. LWT-Food Science and Technology, 36, 263-271. https://doi.org/10.1016/S0023-6438(02)00226-8

[15] Aremu, S.O. and Nweze, C.C. (2017) Determination of Vitamin A Content from Selected Nigerian Fruits Using Spectrophotometric Method. Bangladesh Journal of Scientific and Industrial Research, 52, 153-158.

https://doi.org/10.3329/bjsir.v52i2.32940

[16] Hasan, M.N., Akhtaruzzaman, M. and Sultan, M.Z. (2013) Estimation of Vitamins B-Complex (B2, B3, B5 and B6) of Some Leafy Vegetables Indigenous to Bangladesh by HPLC Method. Journal of Analytical Sciences, Methods and Instrumentation, 3, 24-29. https://doi.org/10.4236/jasmi.2013.33A004

[17] Abbas, M., Habibullah and Shah, H.U. (2007) Proximate and Mineral Composition of Mung Bean. Sarhad Journal of Agriculture, 23, 463-466.

[18] Gopalan, C., Rama Sastri, B.V. and Balasubramanian, S.C. (1993) Nutritive Value of Indian Foods. National Institute of Nutrition, Hydrerabad.

[19] Tosh, S.M., Farnworth, E.R., Brummer, Y., Duncan, A.M., Wright, A.J. and Boye, 
J.I. (2013) Nutritional Profile and Carbohydrate Characterization of Spray-Dried Lentil, Pea and Chickpea Ingredients. Foods, 2, 338-349.

https://doi.org/10.3390/foods2030338

[20] Margier, M., Georgé, S., Hafnaoui, N., Remond, D., Nowicki, M., Chaffaut, L.D., Amiot, M.J. and Reboul, E. (2018) Nutritional Composition and Bioactive Content of Legumes: Characterization of Pulses Frequently Consumed in France and Effect of the Cooking Method. Nutrients, 10, 1668. https://doi.org/10.3390/nu10111668

[21] Tiwari, B.K. and Singh, N. (2012) Pulse Chemistry and Technology. Royal Society of Chemistry, London.

[22] Paul, T., Mozumder, N.H.M.R., Sayed, M.A. and Akhtaruzzaman, M. (2011) Proximate Compositions, Mineral Contents and Determination of Protease Activity from Green Gram (Vigna radiata L. Wilczek). Bangladesh Research Publications Journal, 5, 207-213.

[23] Yadilal, G., Manisha, M., Pavani, E., Navya, M., Alekhya, C., Chandini, G.H. and Madhu, C. (2017) Estimation of Crude Fibre Content in Spices and Fruits. Indo American Journal of Pharmaceutical Sciences, 4, 3864-3868.

[24] De Berrios, J.J., Morales, P., Camara, M. and Sanchez-Mata, M.C. (2010) Carbohydrate Composition of Raw and Extruded Pulse Flours. Food Research International, 43, 531-536. https://doi.org/10.1016/j.foodres.2009.09.035

[25] Chino, X.S., Martínez, C.J., Ortiz, G.D., González, I.A. and Bujaidar, E.M. (2015) Nutrient and Nonnutrient Components of Legumes, and Its Chemopreventive Activity: A Review. Nutrition and Cancer, 67, 401-410. https://doi.org/10.1080/01635581.2015.1004729

[26] Shweta, K., Shobha, A.U. and Padmini, G. (2010) Polyphenols and Tannins in Indian Pulses: Effect of Soaking, Germination and Pressure Cooking. Food Research International, 43, 526-530. https://doi.org/10.1016/j.foodres.2009.09.036

[27] Parikh, B. and Patel, V.H. (2018) Total Phenolic Content and Total Antioxidant Capacity of Common Indian Pulses and Split Pulses. Journal of Food Science and Technology, 55, 1499-1507. https://doi.org/10.1007/s13197-018-3066-5

[28] Jagdish, S. and Partha Sarathi, B. (2012) Non-Nutritive Bioactive Compounds in Pulses and Their Impact on Human Health: An Overview. Food and Nutrition Sciences, 3, 1664-1672. https://doi.org/10.4236/fns.2012.312218

[29] Marijan, S. and Ivana, T. (2017) Influence of Chemical Structure of Some Flavonols on Their Electrochemical Behaviour. International Journal of Electrochemical Science, 12, 7616-7637. https://doi.org/10.20964/2017.08.79

[30] Jain, A.K., Kumar, S. and Panwar, J.D.S. (2009) Antinutritional Factors and Their Detoxification in Pulses-A Review. Agricultural Reviews, 30, 64-70.

[31] Ramadhan, O. and Ian, F.P. (2012) The Biological Significance of Vitamin A in Humans: A Review of Nutritional Aspects and Clinical Considerations. ScienceJet, 1, 1-13.

[32] El-qudah, J.M. (2014) Estimation of Carotenoid Contents of Selected Mediterranean Legumes by HPLC. World Journal of Medical Sciences, 10, 89-93.

[33] Srividya, M. and Chandra (2015) Evaluation of L-Ascorbic Acid, $\beta$-Carotene and Lycopene Contents of Some Fruits of Western Ghats. European Journal of Biomedical and Pharmaceutical Science, 2, 1563-1571.

[34] Jane, B. and Burri (1997) Beta-Carotene and Human Health: A Review of Current Research. Nutrition Research, 17, 547-580.

https://doi.org/10.1016/S0271-5317(97)00011-0 
[35] Nishaa, S., Vishnupriya, M., Sasikumar, J.M., Christabel, H.P. and Gopalakrishnan, V.K. (2012) Antioxidant Activity of Ethanolic Extract of Maranta arundinacea L. Tuberous Rhizomes. Asian Journal of Pharmaceutical and Clinical Research, 5, 3-6.

[36] Sreermulu, D., vijaya Kumar Reddy, C. and Raghunath, M. (2009) Antioxidant Activity of Commonly Consumed Cereals, Millets, Pulses and Legumes in India. Indian Journal of Biochemistry and Biophysics, 46, 112-115.

[37] Jayanthi, P. and Lalitha, P. (2011) Reducing Power of the Solvent Extracts of Eichhornia crassipes (Mart.) Solms. International Journal of Pharmacy and Pharmaceutical Sciences, 3, 3-5.

[38] Jan, S., Khan, M.R., Rashid, U. and Bokhari, J. (2013) Assessment of Antioxidant Potential, Total Phenolics and Flavonoids of Different Solvent Fractions of Monotheca Buxifolia Fruit. Osong Public Health and Research Perspectives, 4, 246-254. https://doi.org/10.1016/j.phrp.2013.09.003

[39] Pavithra, K. and Vadivukkarasi, S. (2014) Evaluation of Free Radical Scavenging Activity of Various Leaf Extracts from Kedrostis foetidissima (Jacq.) Cogn. Food Science and Human Wellness, 4, 42-46.

[40] Janu, C., Kumar, D.R.S., Reshma, M.V., Jayamurthy, P., Sundaresan, A. and Nisha, P. (2013) Comparative Study on the Total Phenolic Content and Radical Scavenging Activity of Common Edible Vegetable Oils. Journal of Food Biochemistry, 38, 38-49. https://doi.org/10.1111/jfbc. 12023

[41] Aslam, J., Mohajir, M.S., Khan, S.A. and Khan, A.Q. (2008) HPLC Analysis of Water-Soluble Vitamins $\left(\mathrm{B}_{1}, \mathrm{~B}_{2}, \mathrm{~B}_{3}, \mathrm{~B}_{5}, \mathrm{~B}_{6}\right)$ in in Vitro and ex Vitro Germinated Chickpea (Cicer arietinum L.). African Journal of Biotechnology, 7, 2310-2314.

[42] Finglas, P.M. and Faulks, R.M. (1984) The HPLC Analysis of Thiamin and Riboflavin in Potatoes. Food Chemistry, 15, 37-44. https://doi.org/10.1016/0308-8146(84)90037-2

[43] Oba, K. and Moriyama, M. (2008) Comparative Study on the Vitamin C Contents of the Food Legume Seeds. Journal of Nutritional Science and Vitaminology, 54, 1-6. https://doi.org/10.3177/jnsv.54.1

[44] Tressler, D.K. and Mack, G.L. (1936) Factors Influencing the Vitamin C Content of Vegetables. American Journal of Public Health, 26, 905-909. https://doi.org/10.2105/AJPH.26.9.905

[45] Hemalatha, S., Platel, K. and Srinivasan, K. (2007) Zinc and Iron Contents and Their Bioaccessibility in Cereals and Pulses Consumed in India. Food Chemistry, 102, 1328-1336. https://doi.org/10.1016/j.foodchem.2006.07.015

[46] Islam, M.S., Ahmed, M.K. and Mamun, M.H.A. (2014) Heavy Metals in Cereals and Pulses: Health Implications in Bangladesh. Journal of Agricultural and Food Chemistry, 62, 10828-10835. https://doi.org/10.1021/jf502486q

[47] Salama, A. and Radwan, M.A. (2005) Heavy Metals (Cd, Pb) and Trace Elements $(\mathrm{Cu}, \mathrm{Zn})$ Contents in Some Foodstuffs from the Egyptian Market. Emirates Journal of Food and Agriculture, 17, 34-42. https://doi.org/10.9755/ejfa.v12i1.5046

[48] Howe, A., Fung, H.L., Lalor, G., Rattray, R. and Vutchkov, M. (2005) Elemental Composition of Jamaican Foods 1: A Survey of Five Food Crop Categories. Environmental Geochemistry and Health, 27, 19-30. https://doi.org/10.1007/s10653-004-5671-7 